\title{
Od redaktora \\ Etnografia sportu i e-sportu. \\ Metodologiczne doświadczenia z badań terenowych
}

\author{
Wojciech Woźniak \\ Uniwersytet Łódzki
}

DOI: http://dx.doi.org/10.18778/1733-8069.17.1.01

Słowa kluczowe:

sport, e-sport,

etnografia, socjologia,

antropologia kultury

\begin{abstract}
Abstrakt: Artykuł wprowadza w problematykę numeru, koncentrując się szczególnie na sekcji tematycznej: Etnografia sportu i e-sportu. Metodologiczne doświadczenia z badań terenowych. Redaktor zwraca uwagę na główne wątki rozważane we współczesnej literaturze przedmiotu, podkreślając relewantny dobór autorek/autorów i artykułów zgromadzonych we wspomnianej sekcji. Wskazane są także luki w literaturze naukowej dotyczące metodologii etnograficznych badań szeroko rozumianego sportu. Sekcja jest skromną próbą ich wypełnienia. Następnie redaktor wprowadza krótko w problematykę każdego z artykułów zawartych w tomie, zarówno z sekcji tematycznej, jak i sekcji varia.
\end{abstract}

Wojciech Woźniak jest socjologiem. Jego zainteresowania naukowe dotyczą fińskiego modelu społeczno-gospodarczego oraz fińskich polityk publicznych, relacji między sportem a polityką, nierówności społecznych i dyskursu publicznego (szczególnie zjawiska paniki moralnej).

\section{Adres kontaktowy:}

Katedra Socjologii Struktur i Zmian Społecznych

Wydział Ekonomiczno-Socjologiczny, Uniwersytet Łódzki

ul. Rewolucji 1905 r. nr 41/43, 90-214 Łódź

e-mail: wojciech.wozniak@uni.lodz.pl
W 2008 roku w artykule redakcyjnym pod tytułem Ethnography and Physical Culture, wprowadzającym do specjalnego numeru czasopisma „Ethnography”, John Hughson pisał:

Etnograficzne prace wymagają konstruowania narracji, która wiąże się często z subiektywnym podejściem badacza, będącego uczestnikiem opisywanych procesów. Narracyjne pisanie jest szczególnie ważne w przypadku immersyjnego zaangażowania bada- 
cza, co odzwierciedlone jest $\mathrm{w}$ artykułach zebranych w tym tomie. „Narracyjny zwrot” w badaniach jakościowych, takich jak etnografia, skutkuje odchodzeniem autorów od „zajmowania pozycji zdystansowanego widza i przejmowaniu podejścia czującego, cieleśnie obecnego i doświadczającego, wrażliwego obserwatora". W najlepszych aplikacjach takiego podejścia dodaje ono niezbędnego, humanistycznego wymiaru w badaniu etnograficznym. W najgorszych jednak redukuje je do poziomu konfesyjnych opowieści. (Hughson 2008: 422 [tłum. WW], także: Markula, Denison 2005: 166)

Wymienione w cytacie wątpliwości opisują zaledwie jeden aspekt badawczo-metodologicznych dylematów związanych $\mathrm{z}$ terenowymi badaniami etnograficznymi oraz przekuwaniem ich w naukowy tekst. Dylematów szczególnie istotnych z punktu widzenia badań sportu i aktywności fizycznej, gdzie ucieleśnione doświadczenie udziału badacza w obserwowanej i/lub współtworzonej rzeczywistości (w roli uczestnika sportowych wydarzeń, niezależnie, czy chodzi o rolę sportowca, kibica czy aktywnego obserwatora rywalizacji) jest permanentnie obecne. $\mathrm{Z}$ tej perspektywy zaskakuje, jak niewiele jest metodologicznych opracowań poświęconych etnograficznej perspektywie w badaniach sportu i aktywności fizycznej. Brakuje również tematycznych zbiorów tekstów omawiających szczegółowo studia przypadku koncentrujące się na metodologicznych aspektach oraz prac przekrojowych, koncentrujących się na jednym podejściu, metodzie i specyfice etnograficznego rzemiosła (a nie konkretnym wymiarze badanej rzeczywistości, np. płci, performansie, kontuzjach, przemocy, karnawalizacji itd.).

Dzieje się tak, pomimo że, jak wskazują Molnar i Purdy (2016: 1) we wprowadzeniu do zbioru Ethnographies in Sport and Exercise Research - będącego tu chlubnym wyjątkiem - liczba badań tego typu wyraźnie rośnie w ostatnich dwóch dekadach. Jako jedyną pracę monograficzną koncentrującą się per se na metodologii autorzy wskazują Sport Ethnography Roberta R. Sandsa z początku XXI wieku (2002), oceniając ją jednocześnie jako „kluczową” i „nieco hagiograficzną” (wobec omawianej metody [Molnar, Purdy 2016: 2]). Przykłady etnograficznych prac pojawiają się również $\mathrm{w}$ tomie obejmującym szersze spektrum jakościowej metodologii i jej okołosportowych aplikacji wydanym w 2005 roku: Qualitative Methods in Sports Studies (Andrews, Mason, Silk 2005).

Sekcja oddawanego w ręce czytelników tomu zatytułowana „Etnografia sportu i e-sportu. Metodologiczne doświadczenia $\mathrm{z}$ badań terenowych" stanowi pierwszą, skromną próbę wypełnienia wspomnianej luki w odniesieniu do polskich badań aktywności fizycznej i sportu.

Cytowany na wstępie Hughson sam jest socjologiem, jednak redagowany przez niego numer „Ethnography" zawiera w zbliżonych proporcjach teksty autorstwa socjologów/socjolożek oraz antropologów/antropolożek kulturowych. Przy wszystkich różnicach dotyczących paradygmatów teoretycznych oraz podejść analitycznych i interpretacyjnych (z socjologicznymi ambicjami do uniwersalizowania lub choćby uogólniania wniosków oraz antropologiczną koncentracją na jak najtrafniejszej i najgęstszej jakości idiograficznego opisu) metodologiczne wątpliwości i trudności dotyczące etnograficznego "terenu" są dla obu dyscyplin tożsame. Jest to odzwierciedlone w zawartości sekcji, dwa artykuły są autorstwa socjologów, dwa autorstwa antropolożek.

Te cztery artykuły są dobrym świadectwem różnorodności tematycznej i wielości podejść, prezentują zupełnie różne obszary badawcze. Łączy je to, 
że autorki i autorzy koncentrują się w nich na doświadczeniach z długotrwałych badań terenowych, dzieląc się wiedzą, jak i wątpliwościami. Wątpliwości, dylematy i trudności nieuchronnie pojawiają się w trakcie pracy w terenie. W każdym z tekstów można zatem znaleźć klarowne wskazówki i ostrzeżenia dotyczące stosowanych procedur badawczych, ich zalet i słabości, warunków aplikacji w terenie. Refleksjom o charakterze metodologicznym odnoszącym się do konkretnych kontekstów tematycznych i specyfiki indywidualnych pól badawczych towarzyszą próby szerszego spojrzenia na podejście etnograficzne i jego współczesny status.

Dwa pierwsze artykuły są pokłosiem wieloletnich badań terenowych. Konrad Burdyka w artykule Kilka uwag o terenowym badaniu amatorskich klubów piłkarskich (w nastajacej erze postpandemicznej) podsumowuje metodologiczne doświadczenia płynące z etnograficznych studiów klubów piłkarskich działających na obszarach wiejskich w Polsce (zob. Burdyka 2019). Doświadczenia z wieloletnich badań prowadzonych $\mathrm{w}$ trudnym terenie pozwoliły autorowi sformułować wiele istotnych wniosków oraz rekomendacji dla przyszłych prac badawczych. Istotnym elementem artykułu jest również rozważenie wpływu pandemii COVID-19 na możliwości i warunki realizowania badań etnograficznych zarówno w czasie jej trwania, jak i po jej zakończeniu.

Marcin Zaród w swoich badaniach nad społecznościami hakerskimi wykorzystywał różne jakościowe techniki badawcze, między innymi długotrwałą etnograficzną obserwację uczestniczącą wymagającą stałej obecności w kolektywach hakerskich. Ważnym elementem jego badań była również etnografia zawodów hakerskich oraz zawodów w programowaniu łazików marsjańskich, która wymagała zarówno obserwacji bezpośredniej prowadzonej „w realu” jak i w świecie cyfrowym. Artykuł pod tytułem Tools of the game. Qualitative digital methodologies for the e-sports research poświęcony jest metodologicznym kwestiom związanym z tym drugim trybem prowadzenia badań. Autor odnosi się do różnych podejść badawczych (netografia, wirtualna etnografia, cyfrowa etnografia), omawiając krytycznie ich teoretyczną i metodologiczną relację z socjologią sportu oraz ich relewancję dla badań e-sportu, mediów oraz studiów nad nauką i techniką.

W artykule Karoliny Szymy-Ziembińskiej Ja, ucieleśniona w ruchu, czyli o biegowej drodze z autoetnografia znajdziemy omówienie metodologicznych wątków związanych ze zrealizowanym przez autorke projektem badawczym (omówionym szczegółowiej w: Szyma 2019), będącym autoetnografią doświadczenia biegaczki wyczynowej. To specyficzne studium przypadku pokazuje, że prowadzenie badań tego typu pozwala na włączanie w projekt rozmaitych technik i narzędzi, których zadaniem jest uzupełnienie, wzbogacenie i pogłębienie autoopisu. Autoetnografia zyskuje w ostatnich latach rosnąca popularność, wszyscy zainteresowani tym podejściem znajdą w artykule Szymy-Ziembińskiej wiele informacji na temat przetestowanych w jej badaniu procedur oraz praktycznych sugestii.

Kończący sekcję artykuł Wiki Krauz pod tytułem Jakiej ptci sa piłkarzy(n)ki? Żeński futbol i antropologia zaangażowana podejmuje z kolei kwestię "zaangażowanych nauk społecznych". Łączenie akademickich badań z działalnością społeczną mającą przynieść/umożliwić zmianę społeczną i krytyczne spojrzenie na praktyki kulturowe to zagadnienie i ważne, i trudne, a dla niektórych kontrowersyjne. Być może dlatego rzadko pojawiające się na 
łamach czasopism naukowych podejmujących refleksje metodologiczne. Krytyczna reewaluacja patriarchalnej struktury relacji płci w odniesieniu do świata żeńskiego futbolu, która była celem rekapitulowanego w tekście Krauz działania, pozwoliła jednak przyjrzeć się w szerszej perspektywie interwencji badawczo-artystycznej. Z jednej strony jako narzędziu gromadzenia danych empirycznych i poszerzania wiedzy, z drugiej - jako świadomej i celowej ingerencji w pole, w którym zaangażowany badacz lub badaczka uczestniczy podczas pracy terenowej.

W sekcji ogólnotematycznej czytelniczki i czytelnicy tego tomu znajdą również cztery artykuły.

Dwa pierwsze łączy wątek fiński. W artykule Magdaleny Rek-Woźniak Miasto przemysłowe i usankcjonowany dyskurs dziedzictwa. Porównawcze studium narracji muzealnych w Łodzi $i$ Tampere pojawia się opis i próba interpretacji fundamentalnych różnic pomiędzy sposobami opowiadania "o sobie" w dwóch pod wieloma względami podobnych miastach o stricte przemysłowej genezie. Analizując oficjalnie usankcjonowany dyskurs na temat ich historii, autorka pokazuje również jego współczesne konteksty i uwikłanie w aktualną politykę i dyskurs publiczny na poziomie dwóch społeczności lokalnych.

W drugim artykule $\mathrm{z}$ tego bloku, zatytułowanym Czy można zaprojektować przyszłość? Polityczno-kulturowe korzenie dwudziestowiecznej transformacji Finlandii, Wojciech Woźniak podejmuje temat historycznych procesów, które przyczyniły się do zmiany pozycji Finlandii w systemie świecie i znalezienia się na przełomie XX i XXI wieku w gronie krajów o najwyższym w skali całego globu zaawansowaniu technologicznym i jednej z najbardziej konku- rencyjnych gospodarek. Tekst jest próbą wskazania i interpretacji tych historycznych wydarzeń, które autor uznaje za kluczowe czynniki umożliwiające głęboką transformację fińskiej gospodarki i społeczeństwa w drugiej połowie XX wieku.

Artykuł Pauliny Adamczyk Diagnoza: niemiłość? Działania pozorne a system wsparcia dzieci i młodzieży po próbach samobójczych podejmuje kwestię stosunkowo rzadko pojawiającą się w polskim dyskursie naukowym i debacie politycznej. Jest to dość zaskakujące, biorąc pod uwagę, że zachowania samobójcze należą do klasycznych tematów socjologicznych, a liczba samobójstw w Polsce od lat przekracza liczbę zgonów w wypadkach komunikacyjnych, wśród dzieci i młodzieży będąc drugą najczęstszą przyczyną śmierci. W eseju socjologicznym Adamczyk omówione są różne aspekty tego zjawiska, ze szczególnym uwzględnieniem dwóch. Po pierwsze, problematyki stabuizowanych relacji rodzinnych jako istotnego czynnika tak suicydogennego, jak i wpływającego na proces zdrowienia po próbie samobójczej oraz, po drugie, kwestii instytucjonalnej niewydolności systemu wsparcia dla grup - deklaratywnie - objętych w Polsce szczególną troską.

W zamykającym tom artykule Wykorzystanie wywiadów kognitywnych w projektowaniu kwestionariusza wywiadu na przykładzie badania uczenia się osób dorostych autorki (Paulina Adamczyk, Marika Markowska, Marta Petelewicz, Katarzyna Piotrowska i Joanna Stankowska) podejmują stricte metodologiczną kwestię łączenia jakościowych i ilościowych narzędzi badawczych w jednym projekcie, w celu optymalizacji jakości narzędzia badawczego, a w konsekwencji - uzyskiwanych danych. W rekapitulowanym przedsięwzięciu badawczym wykorzystano narzędzie jakościowego wywiadu 
kognitywnego jako ważny etap procesu projektowania i testowania ilościowego kwestionariusza. Autorki omawiając konkretny przypadek dużego badania ilościowego, analizują relewancję zastoso-

\section{Bibliografia}

Andrews David L., Mason Daniel S., Silk Michael L., eds. (2005)

Qualitative Methods in Sports Studies. Oxford: Berg.

Burdyka Konrad (2019) Między zagroda a boiskiem. Studium aktywności wiejskich klubów sportowych. Warszawa: Wydawnictwo IFiS PAN.

Hughson John (2008) Ethnography and Physical Culture. „Ethnography", vol. 9, no. 4, s. 421-428.

Markula Pirkko, Denison Jim (2005) Sport and the Personal Narrative [w:] David L. Andrews, Daniel S. Mason, Michael L. wanych procedur i ich efektów w celu sformułowania sugestii i zaleceń mogących ułatwić zastosowanie podobnego podejścia w innych projektach badawczych.
Silk, eds., Qualitative Methods in Sports Studies. Oxford: Berg, s. $165-184$.

Molnar Gyozo, Purdy Laura G. (2016) Introduction [w:] Gyozo Molnar, Laura G. Purdy, eds., Ethnographies in Sport and Excercise Research. Abindgdon: Routledge, s. 1-10.

Sands Robert R. (2002) Sport Ethnography. Champaign, IL: Human Kinetics.

Szyma Karolina (2019) Ucieleśnione w ruchu. Polskie biegaczki profesjonalne w perspektywie antropologicznej. Warszawa: Wydawnictwo UW.

\section{Cytowanie}

Woźniak Wojciech (2021) Od redaktora: Etnografia sportu i e-sportu. Metodologiczne doświadczenia z badań terenowych. „Przegląd Socjologii Jakościowej", t. 17, nr 1, s. 6-10 [dostęp dzień, miesiąc, rok]. Dostępny w Internecie: ‘www.przegladsocjologiijakosciowej. org〉. DOI: http://dx.doi.org/10.18778/1733-8069.17.1.01

\section{Editorial: The Ethnography of Sport and E-Sport. Methodological Experiences from the Fieldwork}

Abstract: This article introduces the subject of the thematic issue: The Ethnography of Sport and E-Sport: Methodological Experiences from the Fieldwork. The Editor points to the most crucial threads in the contemporary literature on the subject. He underlines the relevance of the authors and articles collected in this issue. Also indicated are gaps in the academic literature regarding the methodology of ethnographic research into broadly understood sport. The issue is a modest attempt to fulfill these gaps. The Editor also briefly recounts the contents of the articles, both from the thematic section and from the varia section.

Keywords: sport, e-sport, ethnography, sociology, cultural anthropology 